SECTION 11. Biology. Ecology. Veterinary.

Leonid Alexandrovich Chunihin

Ph.D. in Biological Sciences, Associate Professor, Gomel State Medical University, Republic of Belarus

Artur Leonidovich Chehovskii

Graduate student,

Gomel State University named Skaryna, Republic of Belarus chehovskii@mail.ru

Denis Nikolaevich Drozdov Ph.D. in Biological Sciences, Associate Professor, Gomel State University named Skaryna, Republic of Belarus

\title{
OPTIMIZATION APPROACH TO ASSESSING RADON HAZARD TERRITORY OF THE REPUBLIC OF BELARUS
}

\begin{abstract}
The article deals with the problem of natural radioactive gas - radon. Shows the optimization approach to the assessment of radon in the Republic of Belarus.

Keywords: radon, radon index, critical areas radon, lung cancer.

Citation: Chunihin LA, Chehovskii AL, Drozdov DN (2014) OPTIMIZATION APPROACH TO ASSESSING RADON HAZARD TERRITORY OF THE REPUBLIC OF BELARUS. ISJ Theoretical \& Applied Science 9 (17): 85-88. doi: http://dx.doi.org/10.15863/TAS.2014.09.17.15
\end{abstract}

\section{ОПТИМИЗАЦИЯ ПОДХОДА К ОЦЕНКЕ РАДОНООПАСНОСТИ ТЕРРИТОРИИ РЕСПУБЛИКИ БЕЛАРУСЬ}

Аннотация: В статье затрагивается проблема естественного радиоактивного газа - радона. Показана оптимизачия подхода к оченке радоноопасности территории Республики Беларусь.

Ключевые слова: радон, радоновый показатель, критические зоньл радоноопасности, рак легкого.

\section{ВВЕДЕНИЕ}

Проблема радиоактивного газа - природного радона является важной проблемой радиационной медицины, непосредственно касающейся населения многих регионов мира.

Радон - благородный радиоактивный газ, тяжелее воздуха, не имеющий вкуса, цвета и запаха, образующийся в радиоактивной цепочке в процессе распада естественных радионуклидов семейств урана и тория. Согласно оценке Научного комитета по действию атомной радиации (НКДАР) ООН, радон и его дочерние продукты распада (ДПР) определяют примерно $3 / 4$ годовой индивидуальной эффективной дозы облучения, получаемой населением от земных источников радиации [1]. Наиболее значимым и распространенным дозовым фактором является воздействие радона, содержащегося в воздухе помещений. Радон, являясь компонентом воздуха, попадает в легкие человека при дыхании. По данным Всемирной организации здравоохранения, воздействие радона повышает риск возникновения и развития рака легкого [2], вследствие воздействие высокоэнергетического $\alpha$-излучения при распаде радона на высокочувствительные клетки дыхательной системы. По оценкам экспертов Международной комиссии по радиационной защите (МКРЗ) облучение населения за счет радона обуславливает до 20 \% общего количества заболеваний раком легких [3]. 
Существует три естественных радиоактивных изотопа радона: ${ }^{222} \mathrm{Rn}$, или просто радон, образующийся в радиоактивном семействе урана- $238,{ }^{220} \mathrm{Rn}$ или торон, образующийся в семействе тория- 232 , и ${ }^{219} \mathrm{Rn}$, или актион, образующийся в семействе урана-235. Эти изотопы имеют следующие периоды полураспада: 3,82 дня, 55 сек. и 4 сек. соответственно. В связи с этим ${ }^{222} \mathrm{Rn}$, являясь наиболее долгоживущим изотопом радона, вместе с его ДПР вносят наиболее существенный вклад в облучение человека.

Проблемы облучения радоном с его ДПР и радиационной защиты на рабочих местах и в жилищах были рассмотрены в Публикации № 50 МКРЗ, 1987 г. [4] и Публикации № 60 МКР3, 1990 г. [5]. Принципиально новые подходы к оценке радоновой опасности и радиационной защите от радона и его ДПР были показаны в Публикации № 65 МКР3, 1993 г. [6]. Современный подход, медицинские аспекты и более глубокое рассмотрение радоновой опасности описаны в Публикации № 115 МКРЗ «Риск возникновения рака легкого при облучении радоном и продуктами его распада. Заявление по радону» [3]. Такое пристальное внимание различных мировых организации и масштаб проводимых исследований напрямую указывают на важность и остроту радоновой проблемы.

Впервые доказательства связи заболеваемости раком легкого с концентрацией радона в рабочих помещениях были получены по результатам эпидемиологических исследований, проведенных среди работников урановых и других шахт [7]. Выводы, сделанные для категории шахтеров, работающих в условиях повышенных концентраций радона, были распространены согласно линейной беспороговой концепции на область значительно более низких концентраций, наблюдающихся в жилых помещениях. В последствии значения коэффициентов риска, а также поло-возрастные зависимости заболеваемости раком легкого были подтверждены в 13 эпидемиологических исследованиях, проведенных в 9 европейских странах [8]. Также были проранжированы основные причины, вызывающие возникновение и развитие рака легкого [8].

Известно, что основным источником поступления радона в окружающую среду является почва [9]. Впоследствии радон частично растворяется в подземных водах, а также эксхалирует в атмосферу, попадая при этом в помещения построенных зданий через различные негерметичные отверстия, щели, тещины, сколы. В закрытых помещениях радон способен накапливаться, преимущественно в подвалах и на нижних этажах зданий, вследствие более высокой, чем у воздуха, плотности.

Основным показателем радонового риска является превышение предельнодопустимой концентрации радона в воздухе помещений. Для России и Беларуси в качестве показателя принята эквивалентная равновесная объемная активность (ЭРОА) радона и торона, предельно-допустимое значение, которой установлено 200 Бк/ $\mathrm{M}^{3}$ в существующих, и 100 Бк/м ${ }^{3}$ в проектируемых зданиях [10]. Однако Международная комиссия по радиационной защите рекомендует использовать единый уровень ПДК в пределах 100 Бк $/ \mathrm{M}^{3}[3]$.

\section{МАТЕРИАЛЫ И МЕТОДЫ}

Для оптимизации подхода к оценке радоноопасности территории Республики Беларусь было предложено рассмотреть ряд косвенных показателей, которые влияют на концентрацию радона. Материалами являлись проведенные в 1992 г. крупномасштабные скриннинговые исследования по измерению концентрации радона в сельских жилых помещениях Гомельской и Могилевской областей [11], проведенные в 2005 г. исследования в жилых и производственных помещениях при помощи пленочных дозиметров [12].

\section{РЕЗУЛЬТАТЫ ИССЛЕДОВАНИЯ И ИХ ОБСУЖДЕНИЕ}


Одной из ключевых проблем по измерению концентраций радона является значительное колебание этого показателя в серии измерений. Чтобы достоверно определить концентрации радона в помещениях зданий, было предложено проанализировать косвенные факторы, определяющие концентрацию радона. Если принять, что в сельских населенных пунктах преобладают одноэтажные деревянные строения с простыми фундаментами и деревянными полами, то можно считать, что поступление радона в помещение определяется, в основном, свойствами подстилающих пород. Исходя из этого, можно предложить в качестве показателя радоноопасности территории величину, равную произведению показателей, обуславливающих наличия радона в почвах и породах, в относительных единицах: мощность дозы дочернобыльского фона (МЭД), запас урана в почвах, проницаемость почв и пород для радона, и глубину залегания первого водоносного горизонта. Полученный радоновый показатель будет отражать потенциальную радоновую опасность территории исходя из фундаментальных геологических характеристик, которые напрямую влияют на концентрации радона.

Исследование показали неравномерность распределения концентрации радона в жилых помещениях по территории Республики Беларусь.

Так, на территории Гомельской области концентрации радона доходили до уровня 1 ПДК, что является потенциально небезопасным. Однако с помощью методики радонового показателя было выявлено, что на данной территории не следует ожидать наличие больших концентраций радона ввиду: бедности почвы ураном (материнская порода для радона), соответственно низкой МЭД, и малой глубину залегания первого водоносного горизонта (поглощение радона). Прогнозируемые уровни радона не должны превышать 0,7 ПДК. Достижение в измерениях уровня 1 ПДК было следствие плохой вентиляции и накопления избытка радона в помещении, на что следует обратить особое внимание. Ведь с геологической точки зрения данная территория не может нести серьезной радоновой опасности, а подобные концентрации являются следствие неграмотной деятельности человека по проектированию жилья и организации бытовых условий. Применение методики радонового показателя помогло правильно скорректировать полученные результаты.

На территории Могилевской области наблюдались уровни радона вплоть до 3 ПДК. В частности по северу и северо-востоку области, где располагается критическая зона по радоноопасности. Однако и здесь показатели были завышены. Данная территория имеет глинистые почвы богатые ураном, но коэффициент проницаемости таких почв крайне мал, что способствует утрате радоном большей части своей активности. Несмотря на это на данной территории вполне могут наблюдаться значения вплоть до 1,5-2 ПДК - что, безусловно, является небезопасным.

На территории Витебской области наблюдались уровне радона до 4 ПДК и более. Причем критические зоны радоноопасности разбросаны по всей территории области. Это обусловлено богатыми ураном почвами и высокими значениями коэффициента проницаемости, что способствует более быстрому прохождению радона через слой почвы и сохранению им значительной части своей активности. Данная область вызывает наибольшее опасение, т.к. в некоторых регионах ее территории имеются неблагоприятные геологические условия, способствующие выделению повышенных концентраций радона, на уровне до 2-3 ПДК, которые, как правило, дополнительно усугубляются деятельностью человека.

\section{ЗАКЛЮЧЕНИЕ}

Радоновые исследования в настоящее время ограничиваются, главным образом, предпроектными гигиеническими оценками территорий строительных площадок жилых и производственных зданий. Такие оценки основаны на весьма небольшой корреляции между измеренной плотностью потока радона с поверхности почвы (Бк/c· $\left.\mathbf{M}^{2}\right)$ и возможной 
концентрацией радона в помещениях зданий (Бк/м³). Концентрация радона в помещениях является весьма вариабельной величиной и зависит от многих факторов. Устойчивая и достоверная корреляция концентрации радона в помещении зданий с плотностью потока радона с поверхности почвы может быть обеспечена при строгом соблюдении условий измерения: одинаковый гранулометрический состав почвы на площадке измерений, влажность почвы и воздуха, параметра температуры воздуха и атмосферного давления, время, прошедшее от выпадения последних осадков, их количества, состояние и тип подпочвенных грунтов и др.. Провести все измерения в одинаковых условиях является трудновыполнимой задачей, также, как и учесть в виде поправок все факторы среды, влияющие на результат измерений. Однако имеется ряд фундаментальных геологических показателей, от которых зависит концентрация радона. Применяя комплекс таких показателей можно охарактеризовать потенциальную радоноопасность территории, и показать усредненные значения концентрации радона, которые могли бы быть получены лишь при очень длительных непрерывных измерениях (в течение года и более). Это особенно важно, ведь облучение радоном и его ДПР протекает хронически на протяжении все жизни, и временные падения или резкие увеличения концентраций радона, полученные в разовых измерениях, могут не соответствовать реальной обстановке радоноопасности, полученной с помощью фундаментальных геологических показателей, от которых напрямую зависит концентрация радона.

\section{References:}

1. Radiatsiya. Dozy effekty risk (1990) Moscow, Mir, 80.

2. Radon i rak: informatsionnyy byulleten' (2005) No.291, Vsemirnaya organizatsiya zdravookhraneniya, Moscow, 4.

3. Risk vozniknoveniya raka legkogo pri obluchenii radonom i produktami ego raspada. Zayavlenie po radonu (2013) pod red. MV Zhukovskogo, SM Kiseleva, AT Gubina, Perevod publikatsii No.115 MKRZ. Moscow, FGBU GNTs FMBTs im. A.I. Burnazyana FMBA Rossii, 92.

4. (1987) ICRP Publication No.50, Oxford: Pergamon Press, 79.

5. (1990) ICRP Publication No.60, Oxford: Pergamon Press, 94.

6. Zashchita ot radona-222 v zhilykh zdaniyakh i na rabochikh mestakh (1995) Publikatsiya No. 65 MKRZ, Moscow, Energoatomizdat, 78.

7. Doll R, Payne P, Waterhouse JAH (1966) Cancer Incidence in Five Continents. Geneva: Vice, Berlin: Springer, 403.

8. Darby D, Hill, etc. (2005) Radon in home and risk of lung cancer: collaborative analysis of individual data from European case-control studies. Br. Med. Jornal, No.330, pp. 223-227.

9. Bekman IN (2000) Radon: vrag, vrach i pomoshchnik. Moscow, MGU, 205.

10. Normy radiatsionnoy bezopasnosti (NRB-2000) (2000) Min-vo Resp. Belarus'. GN 2.6.1.8-127-2000 - Minsk, 112.

11. Otchet o NIR, zakl. (1992) Nauchn.-issl. in-t promyshlennoy i morskoy meditsiny; ruk. EM Krisyuk. St. Petersburg, 205.

12. Otchet o NIR, zakl. (2005) Ob"ed. In-t energeticheskikh i yadernykh issledovaniy; ruk. OI Yaroshevich. Minsk; Obl. Tsentr gigieny, epidemiologii i obshch. zdorov'ya; ruk. VN Bortnovskiy. Gomel', 170. 